\title{
Study on the Associative Character of Dongba Script in Lijiang Area
}

\author{
Yin Zhou1,2 \\ ${ }^{1}$ Chinese History Postdoctoral Research Station, Southwest University, Chongqing, China \\ ${ }^{2}$ Humanities College, Chongqing Jiaotong University, Chongqing, China \\ Email: zhouyin2008@126.com
}

How to cite this paper: Zhou, Y. (2019) Study on the Associative Character of Dongba Script in Lijiang Area. Open Access Library Journal, 6: e5255.

https://doi.org/10.4236/oalib.1105255

Received: November 3, 2018

Accepted: February 24, 2019

Published: February 27, 2019

Copyright (c) 2019 by author(s) and Open Access Library Inc.

This work is licensed under the Creative Commons Attribution International License (CC BY 4.0).

http://creativecommons.org/licenses/by/4.0/

\begin{abstract}
Dongba script, which is in the early stages of writing, is an important pictograph, and the study of Dongba script helps to study the origin and development of writing. Through long-time researching on Dongba scripture in Lijiang area, we find that associative character in Dongba script is special. This article researches on the associative characters in Dongba script.
\end{abstract}

\section{Subject Areas}

Linguistics, Sociology

Keywords

Dongba Script, Associative Character, Lijiang Area

\section{Introduction}

Dongba script is used in religious activities by Naxi's priest-Dongba. Because Dongba script is pictograph and is still in use, it is called the living fossil of human script, and there are nearly 1400 scripts in use. Lijiang, located in the northwest of Yunnan province, is the main settlement of Naxi. Lijiang Dongba culture is prosperous on the history, and there have been many famous Dongba, leaving a lot of beautifully decorated, elegant Dongba manuscript [1] (see Figure $1)$.

The American scholar Joseph Charles Francis Rock had been collecting Dongba manuscripts in Lijiang region and those Dongba manuscripts are now mainly kept in the Harvard-Yenching Institute [2].

Pictograph is the most important feature of Dongba script and the most important script-making method. And when the Dongba has to express more 


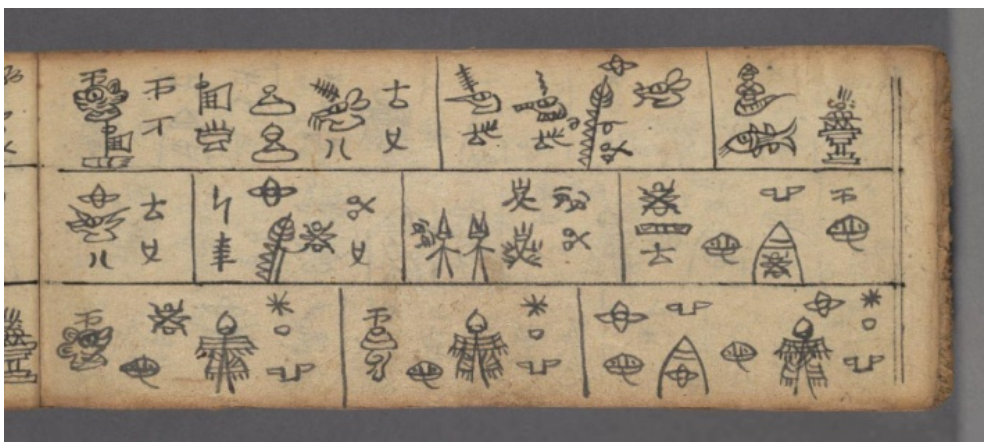

Figure 1. Dongba manuscript.

complicated meaning, they would use another method to create character, such as associative method, inactive method, and picot-phonetic method. Through long-time researching on Dongba scripture in Lijiang area, we find that associative character in Dongba script is special. This article researches on the associative characters in Dongba script.

The materials we use are from "An Annotated Collection of Naxi Dongba Manuscripts" [3] and "An Annotated Collection of Naxi Dongba Manuscripts" [4]. "An Annotated Collection of Naxi Dongba Manuscripts" is the biggest collection of Dongba manuscripts until now, covering almost all areas of Lijiang Dongba manuscripts. The materials quoted from the "An Annotated Collection of Naxi Dongba Manuscript" will be marked with the volume and the page, and "88.190" means that the material comes from volume 88 , page 190 . The materials quoted from the "Naxi Dongba manuscripts collected by Harvard-Yenching Institute" will be marked with the volume and the page, and "H4.250" means that the material comes from volume 4, page 250.

\section{Interpretation Example of Dongba Scriptures in Lijiang Area}

Dongba scriptures, which have been published with a translation, cannot be directly used as research materials in this paper. The published version includes the original content of Dongba scripture, international phonetic, corresponding translation, and Chinese translation, being called "four comparison version". The four comparison version did not explain the origin and the evolution of every character.

The Dongba scripture and the Dongba character should be translated and analyzed character by character, which we call it "Zi Shi". Through "Zi Shi", we can make sure the original pronunciation and meaning, make sure the current pronunciation and meaning, and make sure the evolution of the characters. We will take the Dongba scripture "Awaken the Gods.Sacrifice Food" for example, to show the "Zi Shi".

The Dongba scripture "Awaken the Gods-Sacrifice Food", written by Donglu living in Qihe township, Lijiang city, is selected from "An Annotated Collection of Naxi Dongba Manuscripts", Volume 85. See Figure 2. 


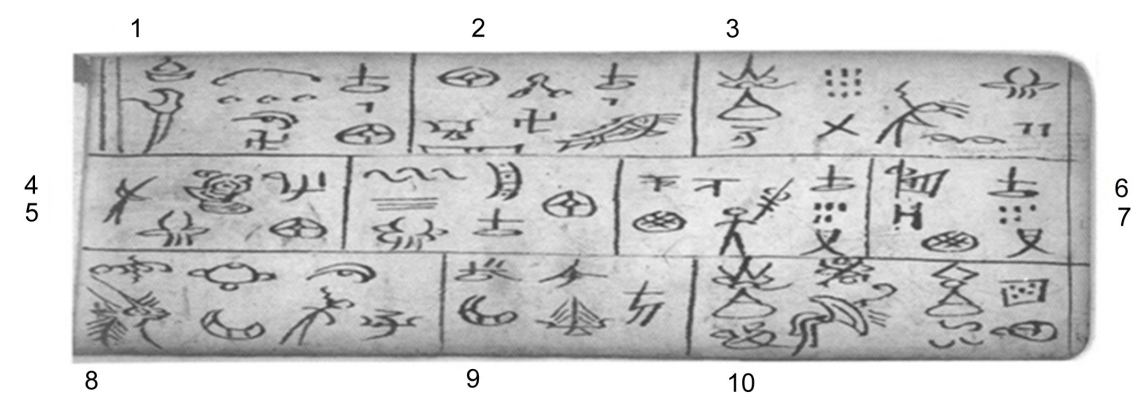

Figure 2. "Awaken the Gods·Sacrifice Food".

\section{ZiShi:}

(1)

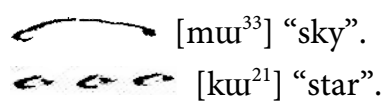

$\Rightarrow\left[\mathrm{ha}^{55}\right]$ "night".

... [ü $\left.{ }^{33}\right]$ "good, kind".

$\pm\left[\mathrm{tsh}^{33}\right.$ ] "hang", phonologically borrowed as demonstrative [tsh $\left.\imath^{33}\right]$ "this".

$7\left[\mathrm{du}^{33}\right]$ "one".

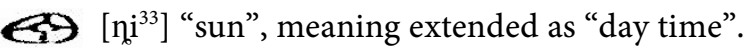

(2)

$\Leftrightarrow\left[n_{\mathrm{i}}{ }^{55}\right]$ "sun", meaning extended as "time".

[t6or $\left.{ }^{33}\right]$ "wine glass", graphic borrowed as position word [t6ər $\left.{ }^{21}\right]$ "up".

[ $\left.\mathrm{dy}^{21}\right]$ "Ground".

S. $\left[\mathrm{zy}^{21}\right]$ "star of zy".

.

$\pm\left[\mathrm{tsh} \imath^{33}\right]$ "hand", graphic borrowed as demonstrative [tsh $\left.\imath^{33}\right]$ "this".

7. $\left[\right.$ dum $\left.^{33}\right]$ "one".

$\left[\mathrm{ni}^{33}\right]$ "fish", graphic borrowedas $\left[\mathrm{ni}^{\mathrm{i}^{3}}\right]$ "day".

(3)

选 $\left[\mathrm{py}^{33} \mathrm{bv}^{21}\right]$ Dongba,the priest of "naxi".

-5 $\left[\mathrm{lum}^{55}\right]$ Geba character.

$\vdots: !\left[\mathrm{gv}^{33}\right]$ “nine".

$\chi\left[\right.$ tshe $\left.^{21}\right]$ "ten", it reads as $\left[\right.$ tshor $\left.^{21}\right]$ here.

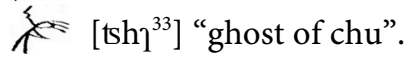

[i $\left.{ }^{21}\right]$ "tobacco leaf", graphic borrowed as "ghost of you".

(3) $\left[\mathrm{pv}^{55}\right]$ "caldron", graphic borrowed as $\left[\mathrm{pv}^{55}\right]$ "sent".

7 [ $\left[\mathrm{ni}^{33}\right]$ "two", graphic borrowed as $\left[\mathrm{ni}^{33}\right]$ "time, day".

(4)

\& [tər $\left.{ }^{21}\right]$ "ghost of Dai".

Sit $\left[\mathrm{pv}^{55}\right]$ "caldron", graphic borrowed as $\left[\mathrm{pv}^{55}\right]$ "send".

[la 33 "tiger", graphic borrowed as $\left[\mathrm{la}^{33}\right]$ "ghost of Lao".

Sif $\left[\mathrm{pv}^{55}\right]$ "caldron", graphic borrowed as $\left[\mathrm{pv}^{55}\right]$ "send".

U! $\left[\mathrm{bu}^{21}\right]$ "Half liter", graphic borrowed as [bur $\left.{ }^{33}\right]$ "will”. 
$\Leftrightarrow\left[\mathrm{ni}^{33}\right]$ "Sun", meaning extended as $\left[\mathrm{ni}^{33}{ }^{33}\right.$ "time, day".

(5)

ヘレ $\left[\mathrm{tci}^{21}\right]$ "cloud".

$=\left[\right.$ hrr $\left.^{33}\right]$ "wind".

>

) $\left[\mathrm{bu}^{21} \mathrm{ku}^{55}\right]$ "waistband", graphic borrowed as [bur $\left.{ }^{33}\right]$ "will”.

$\pm\left[\operatorname{tsh}^{33}\right]$ "hang", graphic borrowed as demonstrative $\left[\operatorname{tsh}^{23}{ }^{33}\right.$ "this".

(4) $\left[\mathrm{no}^{\mathrm{i}}{ }^{33}\right]$ "sun", meaning extended as "day time".

(6)

" [phər $\left.{ }^{21}\right]$ "untie", graphic borrowed as [phər $\left.{ }^{21}\right]$ "god of Pan".

$£\left[\mathrm{mu}^{21}\right]$ "dustpan", graphic borrowed as $\left[\mathrm{mu}^{21}\right]$ "soldier".

ᄀ [sæe ${ }^{21}$ " $g o d$ of shan".

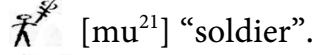

$\pm\left[\operatorname{tah} \imath^{33}\right]$ "hang".

:: [ $\left.\mathrm{ua}^{21}\right]$ "five". The two characters above read as $\left[\operatorname{tshh}^{33} \mathrm{ua}^{21}\right]$, borrowing sound to express the meaning "all".

叉 $\left[\mathrm{me}^{33}\right]$ "Female genitalia", graphic borrowed asparticle $\left[\mathrm{me}^{33}\right]$.

(7)

解 $\left.{ }^{33}\right]$ "the god of victory", also translated as "the god of Ga".

$H\left[\mathrm{u}^{21}\right]$ this is Geba character, and graphic borrowed as $\left[\mathrm{u}^{21}\right]$ "the god of Wu".

[mu $\left.{ }^{21}\right]$ "dustpan", graphic borrowed as $\left[\mathrm{mu}^{21}\right]$ "soldier".

上 $\left[\operatorname{tsh} \imath^{33}\right]$ "hang".

:: $\left[\mathrm{ua}^{21}\right]$ "five". The two characters above read as $\left[\operatorname{tsh}^{33} \mathrm{ua}^{21}\right]$, borrowing sound to express the meaning "all".

又 $\left[\mathrm{me}^{33}\right]$ "Female genitalia", graphic borrowed as particle $\left[\mathrm{me}^{33}\right]$.

(8)

[khv ${ }^{33}$ "mow", graphic borrowed as $\left[\mathrm{khv}^{55}\right]$ "night".

$\left[\mathrm{i}^{33}\right]$ "Mule or Hinny".

D. [du $\left.{ }^{21}\right]$ "big", graphic borrowed as $\left[\mathrm{du}^{33}\right]$ "one".

Wo $\left[\mathrm{ky}^{33}\right]$ "bracelet", graphic borrowed as $\left[\mathrm{k}^{21} \mathrm{y}^{21}\right.$ "night".

$\Rightarrow\left[\mathrm{ha}^{55}\right]$ "night", meaning extended as "rest".

t $\left[{ }^{55}\right]$ "sleep", meaning extended as "rest".

$36\left[\mathrm{se}^{21}\right]$ this is Geba character, and graphic borrowed as modal [se $\left.{ }^{21}\right]$.

(9)

Lef. [so $\left.{ }^{21}\right]$ "big steelyard".

6o $\left[\mathrm{d}^{33} \mathrm{y}^{33}\right.$ "bracelet".

4. $\left[\mathrm{mu}^{33}\right]$ "sky".

贷 $\left[\mathrm{s}^{55}\right]$ "the basket of house god".

灰 $\left[\mathrm{tu}^{33}\right]$ "rise". The five characters above read as $\left[\mathrm{so}^{21} \mathrm{tcy}^{21} \mathrm{mu}^{33} \mathrm{~s}^{55} \mathrm{tu}^{33}\right]$, meaning "the second morning".

资 $\left[\mathrm{py}^{33} \mathrm{bv}^{21}\right]$ “Dongba, the priest of Naxi”. 
23. $\left[\mathrm{nu}^{33}\right]$ "heart", graphic borrowed as a particle $\left[\mathrm{nu}^{33}\right]$.

然 $\left[\mathrm{h} \mathfrak{x}^{21}\right]$ "golden".

舟 7 ? $\left[\mathrm{tcor}^{33} l ə \mathrm{r}^{21}\right]$ "boll made of Board".

ㄴ. $\left[\mathrm{i}^{21}\right]$ "Egg leaked".

제 $\left[\mathrm{s}^{33}\right]$ "dice". The two characters read as $\left[\mathrm{i}^{55} \mathrm{~s}^{33}\right]$, borrowing sound to express the meaning "awake".

$\infty\left[\mathrm{sh}_{1}^{21}\right]$ "shoulder blade", graphic borrowedas [tsh $\left.{ }^{21}\right]$ "come".

Translation:

(1) when Fairy's night and Starlight is beautiful, (2) when the life in the daytime and three stars in the night is good, (3) "Ligu" Dongba will send ninety "Chu" ghost away, (4) will send "Dai" ghost, "Lao" ghost, (5) "Cloud" ghost and "Wind" ghost away. (6) "Ligu" Dongba lets soldier of "Pan" god, "Shan" god, (7) "Ga" god and "Wu" god, (8) have a rest for one night. (9) This morning, (10) "Ligu" Dongba shakes yellow board boll, awaking the sleeping god.

\section{Associative Character and Its Types}

Associative character is composed of several characters or composed of characters and symbols. The meaning of associative character is composed by all the parts, and every part plays an indispensable role in expressing the meaning.

\subsection{Dividing from the Similarities and Differences of Components}

\subsubsection{Associative Character with the Same Texts}

This type of associative character can be divided into two kinds: one kind is composed by the same components, and the same direction; the other kind is composed of the same components, but the opposite position.

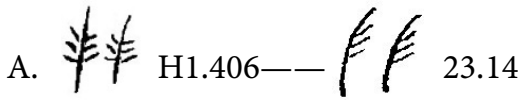

The characters above are associative characters. The first character is composed by two trees, expressing the meaning of "forest". The second also assemble two plants, expressing the meaning of "forest". This character is composed by the same components, and the same direction.

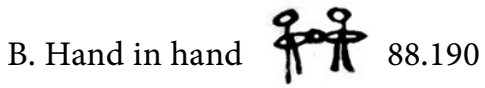

The character is composed of two people. The two people each out their hands, expressing the meaning of "hand in hand". This character is composed by the same components, but the opposite position.
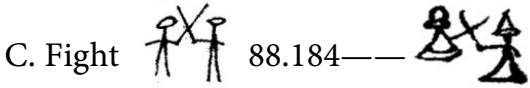

The first character is created by the shape of two people fighting with wooden sticks, expressing the meaning of "fight"; and the second character is more specific, 8 is ancestor called "Youladingrui", and is ghost of "du", and in this character, ancestor called "Youladingrui" and ghost of "du" fight with the wooden sticks, expressing the meaning of "fight".

This character is composed by the same components, but the opposite position. 


\subsubsection{Associative Character with the Different Texts}

Associative character with the different texts, obviously, is composed by different texts.

$$
\text { A. Rain JJ' H4.477-— G2J' } 37.11
$$

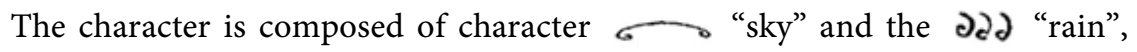
the shape of rains falling from the sky, expressing the verb meaning of "rain".

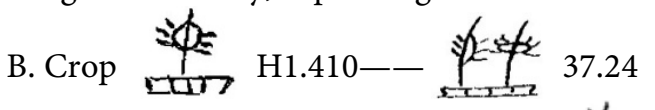

The first character is composed by "enth" and "wheat", and the second character is composed by "erth", 泟 "rice" and "wheat". These characters combine together, forming a new character, and expressing the meaning of "crop".

$$
\text { C. Soldier 条 } 88.181 \text { - 嘴 } 88.182
$$

The first character is composed of takes the arms", expressing the meaning of "soldier". And the second character is composed by expressing the meaning of "soldier". Both of the characters hold the same style of expressing the meaning, except the body of the man is different.

D. Host family<smiles>C1C2C3C4C1C1C2C3C41</smiles>

H1.390

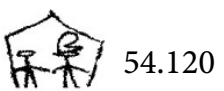

The character is composed of $\$$ "house", 瓜 “man" and "woman". The combination shows "a male and a female in the house", expressing the meaning of "host family". The second character is almost the same.

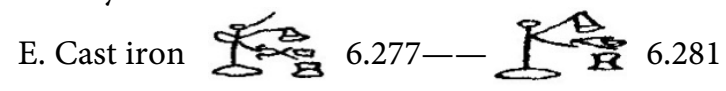

The combined character shows a man carries the tools to cast iron, expressing the meaning of "cast iron".

$$
\text { F. Make plow } \frac{\Delta}{2} 6.278
$$

The combined character shows a man carries the tools to make plow, expressing the meaning of "make plow".

\subsection{Dividing from the Method That the Component Similarities and Differences of Components}

\subsubsection{The Style of "Hui Xing"}

Two or more characters combine together, forming a new character, and expressing a new meaning. The meaning of the new forming character is compose by every component, and all the components take part in expressing the meaning with the iroriginal meaning, so we can deduce the meaning when we see the new forming character.

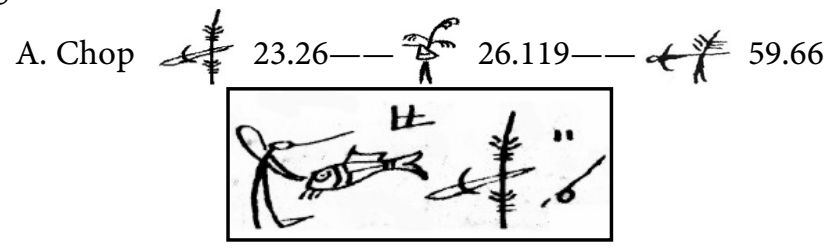


The translation of this scripture is "young people go fishing, and get 'duo' ghost of fish without fin; young people go chopping bamboo, and get 'duo' ghost of bamboo with two bifurcation".

The new forming character "fish" is composed by "man" and "fish"; the new forming character "chop bamboo", is composed by "knife" and "bamboo".

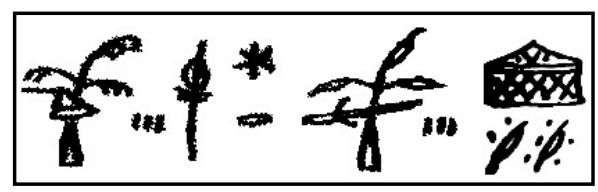

26.119

The translation of this scripture is "chop three spruce trees, and make thousands of spears; chop three chestnuts, and make thousands of broadswords that wave like flying leaves".

The new forming character is composed by "ax" and "spruce tree", expressing the meaning of "chop"; is composed by "knife" and "chest nuts", expressing the meaning of "chop".

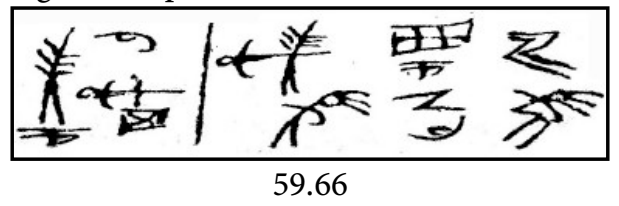

The translation of the scripture is "When chopping trees, don't chop white trees, and chop black trees belonging to ghost; don't chop the white silk bridge, chop the ghost's trunk".

The first "chop" use picto-phonetic character composed by and The second character use associative character $+*$, composed by $\leftarrow$ and $f$.

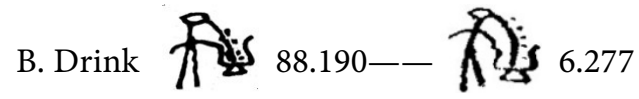

The character looks like a picture that a man drinks from the cup with the straw, and there are drops around the straw, showing that the wine is flowing.

$$
\text { C. Burning incense 施 } 21.4
$$

The character is composed by $\boldsymbol{\mu}$, and $\boldsymbol{s} ;$. The character means "cypress branches", which is usually used in sacrifice ceremony.

\subsubsection{The Style of "Xing Yi"}

The style of "Xing Yi" means that the character is composed by two parts. Compared with the style of "Hui Xing", the way of the components take part in expressing the meaning is different in the style of "Xing Yi". One component composed with the original meaning, and one component composed with the extended meaning at least. 
The character is composed by two parts, the first part 3JJ and the second Character 3JJ means "rain", and character means "month", forming the character of " "5ु)" summer. And the original meaning of is "moon", and "month" is the extended meaning.

But the style of "Xing Yi" is less in Lijiang Dongba script.

\subsection{Dividing from the Nature of the Components}

According to the nature of the components, we can divide associative character into two styles: one style is combined by characters, and the other is combined by character and pictogram symbol.

\subsubsection{Character + Character}
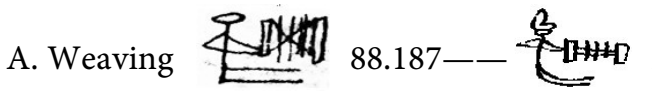

The character is composed by and and means linen. And the two characters combined into one new character, meaning weaving.
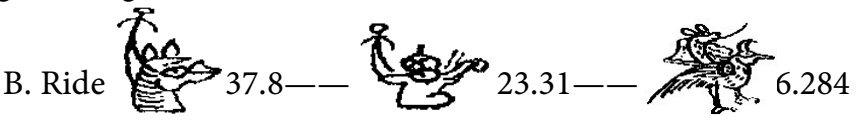

The first character means ride the horse, and the second character means ride the elephant. The two character above is composed by and the riding animals: 掰 fabulous bird. All of them, the meaning "ride" is expressed by subject, object and the position of the subject and object.

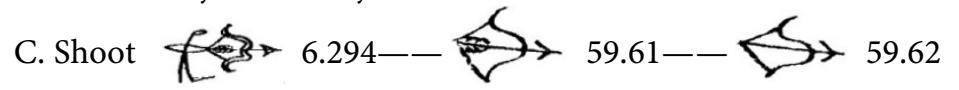

Those three characters mean "shoot", the first character is composed by the people, bow and the arrow. The second and the third composed by the bow and the arrow, expressing the meaning "shoot".

$$
\text { D. Lean against }=\iint^{2 k-2} 23.16
$$

The character is composed by $\&$ and $/ \Gamma^{* k}$, expressing the meaning "lean against" by the subject \& leans against the broken tree $\mathbb{R}^{(k+k}$.

\subsubsection{Character + Pictogram Symbol}

$$
\text { A. Open } 1 \text { H4.255-_ } 54.106
$$

The character is composed by 17 and $\square$ means "door", and $\square$ is

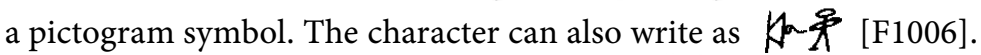

$$
\text { B. } 6.278-1 \longleftarrow 37.3
$$

The character is composed by the means "knife", and $>$ is a pictogram symbol, expressing the meaning by using the knife chopping something, and the chopping object is already abstract from the specific object. And we can find character like in the Dongba scripture, the chopping object is specific. 


\section{Characteristics of Lijiang's Associative Character}

\subsection{Large Quantity, and Great Majority Are Style of "Hui Xing"}

There are many associative characters in Dongba characters, and the majority of which are "Hui Xing". "Hui Xing" is the basic style of associative characters.

\subsection{Change Shape of Character According to the Text}

It is a very common phenomenon to change the shapes of character according to the text. For example, the word "chop", now writes $\longleftarrow$ on the whole, but there are specific shapes in the specific context. When it expresses the meaning of "chop the bamboo", it writes when it expresses the meaning of "chop the cedar", it writes it writes $\leftarrow$.

\section{Conclusion}

Dongba script is at an early stage of the development of the character and has important reference value for the formation and development of the character. The method of associative character is an important method of creating character in Dongba script, and it has two significances: for one hand, it helps to express the concept and word that the method of pictograph cannot express; for the other, the method of associative character reflects the psychology of the ancestors who create the character. Dongba scripture is the Memory of the World, and it is of great significance to carry out systematic research on Dongba script.

\section{Sponsored}

This article is sponsored by Chongqing Postdoctoral Special Fund Project (Item Number: Xm2017153), Chinese Postdoctoral Science Fund Project (Item Number: 2016M602621), and Chongqing Education Commission Social Science Fund Project (18SKGH054).

\section{Conflicts of Interest}

The author declares no conflicts of interest regarding the publication of this paper.

\section{References}

[1] Fang, G.Y. and He, Z.W. (2005) Word Spectrum of Naxi Pictograph. Yunnan Renming Press, Kunming, 42-44.

[2] Li, L.C. (1984) The Mo-So Classic Collected in Library of Congress. In: Li, L.C., Ed., The Theses of Mo-So Study, Taiwan Palace Museum Press, Taiwan, 127-160.

[3] The Institute of Domba Culture (1999) The Collected Works of Naxi Domba Manuscripts. Yunnan Renming Press, Kunming.

[4] Institute of Ethnology and Anthropology, Chinese Academy of Social Sciences (2011) Naxi Dongba Manuscripts Collected by Harvard-Yenching Institute. China Social Sciences Press, Beijing. 